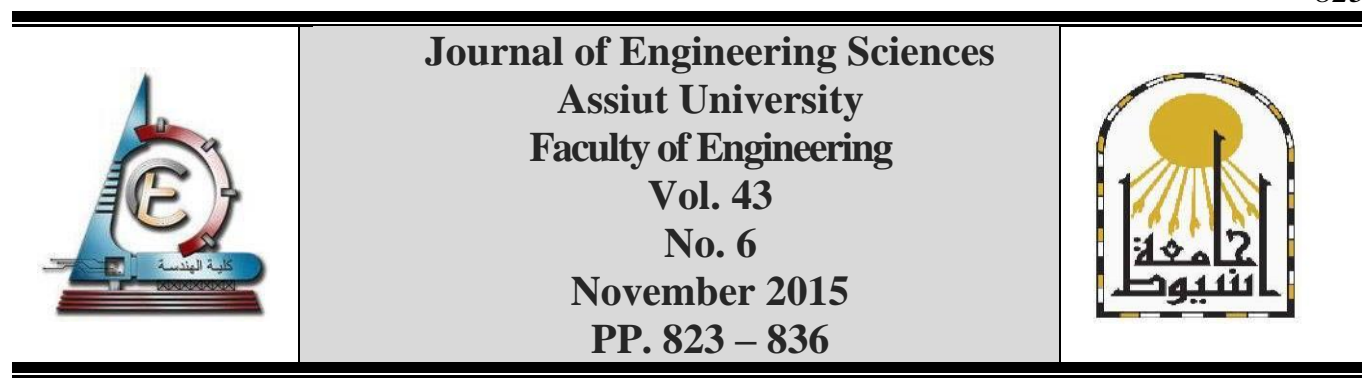

\title{
PERFORMANCE OF MASONRY ARCHES STRENGTHENED WITH CFRP SANDWICH
}

\author{
Ahmed M. Anwar \\ Construction Research Institute, Cairo, Egypt
}

(Received 28 September 2015; Accepted 20 October 2015)

\begin{abstract}
Upgrading and strengthening of structural and architectural arches for functionality purpose as well as for conversation of cultural heritage are of great concern. In the current research, Carbon Fiber Reinforced Polymers (CFRP) was used to raise the structural integrity of masonry arches. The strengthening efficiency and structural performance of arches having semi-circle and quarter circle shapes covering the same opening span were studied. Strengthening by fitting CFRP sheets in a Sandwich form was investigated. At the beginning, CFRP sheets alone were directly applied along the intrados and extrados surfaces of the arches. Secondly, the same technique was adopted but after adding a thin layer of plain concrete at the extrados surface prior to the application of the external layer of CFRP. Six Arches with different strengthening configurations were prepared. Comprehensive static and dynamic evaluations were conducted. The efficiency of strengthened arches with semi-circle shape was found, in general, better than arches of quarter circle shape. CFRP works on prevention of the formation of hinges in either the extrados or intrados surfaces of the arches, and consequently improving the performance of arches during failure. The load carrying capacity was also enhanced significantly. The addition of thin plain concrete layer was found significant in distributing the applied load and preventing the conventional slippage failure mode at interface between mortar and bricks. The obtained dynamic modal parameters of the examined arches due to excitation with light impact hummer at the crest of strengthened arches showed enhancement in their dynamic performance as well.
\end{abstract}

Keywords: Masonry Arches, CFRP strengthening, Physical modeling, Collapse, Damage, Dynamic analysis.

\section{Introduction}

Masonry arches played an important role in construction of a wide range of hydraulic structures in Egypt. Arches constitute not only the fundamental constructive element in transmitting the traffic loads to the carrying systems but also are of considerable historical and architectural importance. Aging problems, accidental problems and/or the need to increase arch carrying capacity are among the challenges that should be put into focus. In addition, masonry arches are scarcely resistant to horizontal loads, and therefore highly vulnerable to seismic actions. Strengthening or repairing of such structures is not always an easy task. The compatibility and adequacy of the chosen material should be studied probably in such a way that the expected brittle failure of masonry should be prevented. Moreover, in 
hydraulic structures the used material should be of durable, light weight, high tensile strength and does not occupy additional volume for hydraulic and navigation aspects.

It has been investigated, by many researchers, the possibility of using fiber reinforced polymers (FRP) sheets directly to masonry constructions [1, 2, 3]. The load carrying capacity of masonry arches and vaults can be increased by modifying the collapse mechanism of the structure using strengthening materials externally bonded at the intrados or the extrados surfaces [4]. Cancelliere et al. [1] reported that strengthening the arch with FRP at the extrados surface only was capable to change the failure mechanism from formation of hinges to collapse due to the limit strength of the constituent materials. Tao et al. [2] studied the effect of using FRP as a repair material applied on the intrados of a large model masonry arch bridge of two vents. Juntao Kang et al. [5] reported that the internal forces in a double curved arch bridge have been favorably redistributed by adding reinforced concrete layer at specific portions of the extrados surface of the bridge. Anania et al. [6], introduced a technique based on the use of the composite CFRP applied using a calibrated shape " $\Omega$-Wrap" around a high resistance mortar core realized at the barrel vault extrados as a supporting rib.

Angelo et al. [7] studied analytically the effect of using composite unbonded tendons to the extrados surface of semicircle arch as another alternative for arch strengthening. Furthermore, Francesca et al. [8] studied the behavior of single bricks and small masonry pillars strengthened by means of fabric reinforced cementitious matrix systems made with glass-fiber grids. Garmendia et al. [9] showed that using a basalt textile embedded in an organic matrix known as Basalt Textile-Reinforced Mortar as a reinforcement system for stone arches enhanced their load-bearing capacity and ductility.

Maruccio et al. [10] conducted advanced non-linear simulations of experimental test results to study the interfacial behavior of brittle substrate (masonry) and the thin elastic sheet (FRP) used for strengthening historical arches and vaults. Spinella et al. [11] showed results of in-situ tests carried out on ancient masonry full-scale arch walls after retrofitting by pre-tensioned stainless steel ribbons. Borri et al. [12] reported the effectiveness of using glass and carbon FRP plates placed at the intrados of masonry arches.

Few researches dealt with the dynamic behavior of strengthened arches. In fact, dynamic tests are nondestructive and cause no damage to these structures. Calik et al. [3] identified the dynamic characteristics of the masonry vault before and after repair, using steel fasteners at the peak of vaults. Bayraktar et al. [13] conducted formal modal analysis on eight historical masonry stone arch bridges with different spans to determine their natural frequencies, damping ratios and mode shapes. The dynamic behavior and modal parameters of brick masonry arches strengthened with prepreg polymer composites were experimentally and numerically studied by Cakir and Uysal [14]. Xie et al. [15] used CFRP to strengthen a concrete buried arch against blast applied at its soffit surface only.

In the current research, two different shapes of masonry arches were investigated; the first was semi-circle while the other was quarter circle. The two sets of arches were subjected to different strengthening scenarios. The strengthening techniques depend mainly on using CFRP sheets in the form of a sandwich, i.e. covering bricks at both upper and lower surfaces simultaneously. This methodology was uncovered in previous works. The arches were evaluated using dynamic and static tests. Modal parameters, load carrying capacity, and failure mechanism for each condition were obtained and discussed. In 
addition, numerical modelling using finite element analysis was conducted to validate the obtained modal parameters for the examined arches.

\section{Experimental program}

\subsection{Materials}

In the current research, masonry arches constituted of red clayey solid brick units bonded together with cement mortar. Each brick unit was of dimensions (length $\mathrm{x}$ width $\mathrm{x}$ thickness) equal to $(180 \times 80 \times 60 \mathrm{~mm})$. The average binding mortar thickness was $10 \mathrm{~mm}$. The physical properties for both materials were investigated at their separate and combined states. The compressive strength test was conducted on one unit of bricks laid horizontally, whereas, a mortar cube of dimensions $(70 \times 70 \times 70 \mathrm{~mm})$ was used for this purpose. The flexure strength was determined by adopting four points load test on one brick unit. While mortar specimens of dimensions $(160 \times 40 \times 40 \mathrm{~mm})$ were used for both flexure and splitting tests. For the purpose of strengthening, sheets of CFRP as well as a layer of plain concrete (P.C.) of $50 \mathrm{~mm}$ thickness were used. Uni-directional CFRP sheets, $0.111 \mathrm{~mm}$ thickness was used. As per the manufacturer, the tensile strength, and modulus of elasticity of CFRP are $3400 \mathrm{~N} / \mathrm{mm}^{2}$, and $2.45 \times 10^{5} \mathrm{~N} / \mathrm{mm}^{2}$, respectively. CFRP was pasted on the required surfaces using two compounds epoxy recommended and supplied by manufacturer. The Physical properties of the Epoxy resin are shown in Table 1. For plain concrete, cylinders of diameter, $100 \mathrm{~mm}$, and height, $200 \mathrm{~mm}$, were prepared for compression and splitting tests. Whereas, prisms of dimensions $(500 \times 100 \times 100 \mathrm{~mm})$ were set for four points flexure test. Table 2 , shows the physical properties of the used materials.

Table 1.

Physical Properties of the Bonding Epoxy

\begin{tabular}{|c|c|c|c|c|c|}
\hline Color & $\begin{array}{c}\text { Specific } \\
\text { Gravity }\end{array}$ & $\begin{array}{c}\text { Flexure Strength } \\
\left(\mathbf{N} / \mathbf{m m}^{\mathbf{2}}\right)\end{array}$ & $\begin{array}{c}\text { Tensile Strength } \\
\left(\mathbf{N} / \mathbf{m m}^{\mathbf{2}}\right)\end{array}$ & $\begin{array}{c}\text { Shear Strength } \\
\left(\mathbf{N} / \mathbf{m m}^{\mathbf{2}}\right)\end{array}$ & $\begin{array}{c}\text { Viscosity } \\
(\mathbf{M P a . S})\end{array}$ \\
\hline Blue & $1.17 \pm 0.1$ & 40 & 30 & 10 & 20000 \\
\hline
\end{tabular}

Table 2.

Physical Properties of used Materials

\begin{tabular}{|c|c|c|c|c|}
\hline $\begin{array}{c}\text { Type of } \\
\text { Specimens }\end{array}$ & $\begin{array}{c}\text { Unit Weight } \\
\left(\mathbf{K N} / \mathbf{m}^{\mathbf{3}}\right)\end{array}$ & $\begin{array}{c}\text { Compressive } \\
\text { Strength } \\
\left(\mathbf{N} / \mathbf{m m}^{\mathbf{2}}\right)\end{array}$ & $\begin{array}{c}\text { Flexure Strength } \\
\left(\mathbf{N} / \mathbf{m m}^{\mathbf{2}}\right)\end{array}$ & $\begin{array}{c}\text { Indirect Tensile } \\
\text { Strength } \\
\left(\mathbf{N} / \mathbf{m m}^{\mathbf{2}}\right)\end{array}$ \\
\hline Clayey & 21.0 & 3.5 & 0.7 & -- \\
\hline Cement & 22.5 & 15.0 & 2.5 & 1.3 \\
\hline Plain & 23.1 & 23.0 & 2.9 & 2.1 \\
\hline
\end{tabular}

In addition, sets of combined bricks and mortar were prepared to determine the properties of their combined actions. Firstly, the compressive strength of a set of three overlaying bricks was examined (Figure 1a). It was found that compressive strength was $3.22 \mathrm{~N} / \mathrm{mm}^{2}$. Secondly, the interfacial shear strength between the mortar and the bricks were also examined experimentally. Three bricks were joined in such a way that the middle brick was oriented ahead of the two edge blocks with an overlap splice length of $100 \mathrm{~mm}$ (Figure 1b). The interfacial shear strength between mortar and bricks were found $0.74 \mathrm{~N} / \mathrm{mm}^{2}$. For all these combined samples, replicates of three were prepared for examination. 


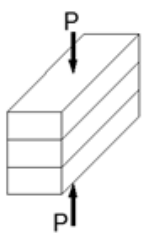

(a)

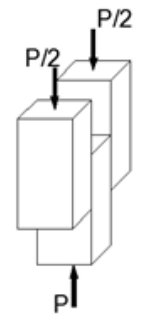

(b)

Fig. 1. Masonry Specimens used for: a) Compression Test, and b) Interfacial Shear Test.

\subsection{Specimens preparation}

\subsubsection{Masonry beams}

At the beginning, the suggested sandwich strengthening by applying, simultaneously, CFRP sheets at the upper and lower surfaces of masonry beams was conducted. Seven bricks were arranged along their width and bonded together with mortar to form masonry beams. The total flexure span was adjusted to $420 \mathrm{~mm}$. Replicates of three were prepared to examine the efficiency of the suggested strengthening. The flexure strength of the beams was examined under four points flexure test. Figure 2, shows the specimens with different strengthening configurations. First, the specimen with no strengthening (hereinafter referred to as "MAS") was examined and kept as a control for comparison. Furthermore, another two sets were prepared to simulate the strengthening conditions that will be used later for the masonry arches. The first was to apply CFRP directly on both the soffit and upper surfaces of masonry beam (hereinafter referred to as "MAS_CFRP"). For the last strengthening configuration (hereinafter referred to as "MAS_CFRP_CONC"), a thin layer of plain concrete was added prior to the application of CFRP at the upper surface of the beam.

In fact, plain concrete was added in the second day of constructing the masonry beams and left in normal room temperature to cure together by daily sprinkling of water on them. Moreover, CFRP was applied after 21 days of concrete casting. The required surface was polished followed by water and air cleaning. The masonry beams were kept for complete dryness for one day. Finally, epoxy (hardener and resign) was applied in two coats - above and underneath the CFRP sheet. Special steel roller was used to ensure the absence of any air voids and ensure full contact. The specimens were kept to cure together till the end of the 28 days. The upper CFRP sheets were used to conform to the same strengthening condition used with arches, as the target was to investigate the enhancement in the group actions of masonry strengthened in sandwich form.
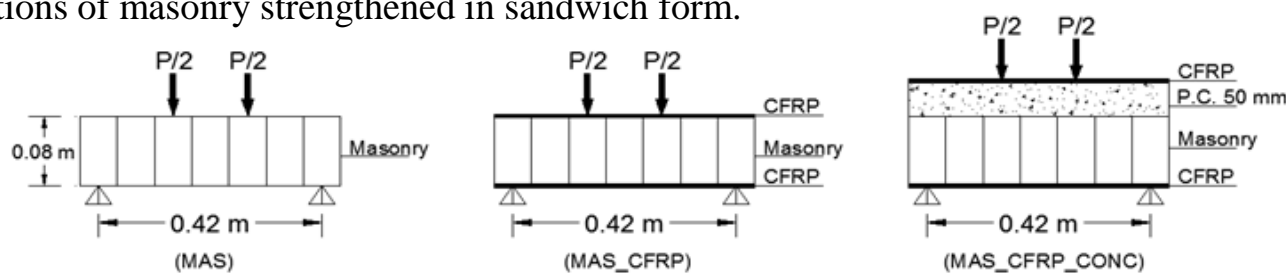

Fig. 2. Different Strengthening Configurations for Masonry Beams

\subsubsection{Masonry arches}

Masonry arches with different geometries and subjected to different strengthening condition were chosen for examination. Mainly, two basic groups of arches with different geometries were investigated. The first was the semi-circle arch (S-Arch) while the second 
arch was of quarter circle (Q-Arch) shape. Particularly, the selected arches were chosen to simulate a wide range of circular masonry arches used in hydraulic structures in Egypt. Additionally, the response of (Q-Arch) was rarely investigated in past researches; therefore it is of great importance to monitor the effectiveness of strengthening on arches with different curvatures. The two groups of arches were chosen to cover the same opening span. Figure 3, shows the geometry for the used arches. A thin layer of plaster mortar, 10 $\mathrm{mm}$, was adopted above and under the bricks. Especial steel molds were used to produce arches with identical shapes. The same procedure for curing and strengthening adopted with the masonry beams were followed. Figure 4, shows the arches during construction. In order to prevent the horizontal movement at the base of the arches, a rectangular plane frame consisted of steel angles [L50x50x5 mm] was used for that purpose.

Each group consisted of three arches. The first arch was kept as control with no strengthening; the second arch was strengthened by applying CFRP layers above and under the masonry arches representing a sandwich, only one unidirectional sheet was applied. Finally the previous strengthening was again adopted but after the addition of $50 \mathrm{~mm}$ plain concrete layer on the top surface of the arch prior to the application of the upper CFRP sheet. In order to ensure full contact between the masonry arch and the plain concrete, steel nails (length $=50 \mathrm{~mm}$, and diameter $=4 \mathrm{~mm}$ ) were inserted in the mortar between brick blocks during construction. The nails were put in staggered way with a maximum spacing of $200 \mathrm{~mm}$. the lateral movement of the added concrete was also prevented by making further wrapping of a $50 \mathrm{~mm}$ CFRP strip at the base of the arch. Figure 5, shows the different strengthening configurations for the arches of (S-Arch) shape. The same strengthening configurations were adopted for arches of (Q-Arch) shape. Table 3, shows all strengthening data for both arches, (S-Arch) and (Q-Arch), respectively.
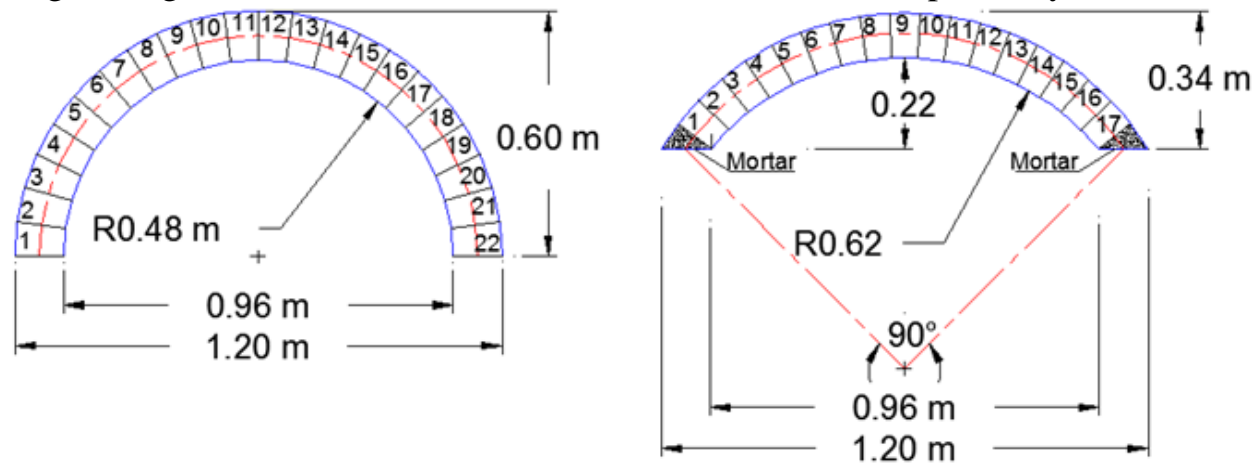

Fig. 3. Geometry of the Used Semi-Circle and Quarter-Circle Arches

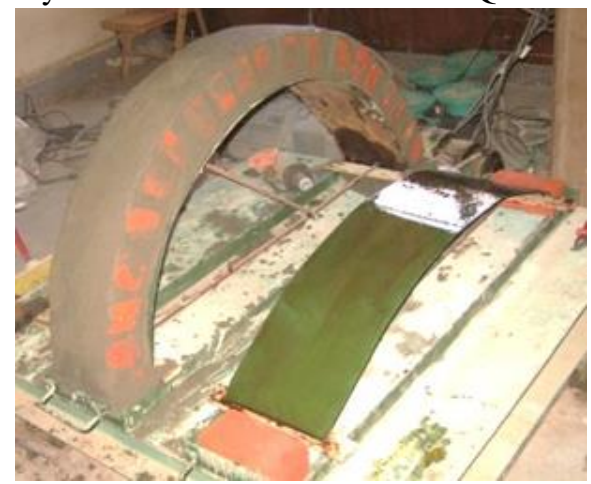

Fig. 4. Arches during Construction 


\subsection{Test setup}

The arches were examined first statically. A concentrated load was applied at the crest of the arch. Both load and mid-span deflections were measured. The load-deflection plots for each strengthening condition were put into glance and compared together. The failure mode was also reported. On the other hand, dynamic evaluation for all arches was performed. All the arches were subjected to vertical impulse by a light impact hammer applied at the crest of the arches. For each strengthening condition, the test was performed twice, before and after strengthening. Acceleration time histories were collected by means of piezoelectric accelerometer vertically placed at the top of the arch. The collected data were filtered and analyzed using Fast Fourier Transformation (FFT) technique. The natural frequencies were obtained and compared with each other. In the current application, the sampling rate was selected to be $5000 \mathrm{~Hz}$. This allowed the capturing up to the second mode for both arches with sufficient resolution. Figures $6 a$, and $b$, show the test procedure for static and dynamic tests, respectively.

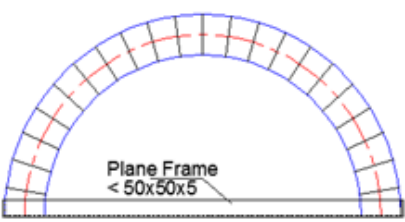

Arch with no strengthening

(S-Arch)

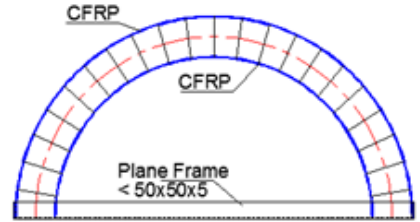

Arch with CFRP strengthening only

(S-Arch-CFRP)

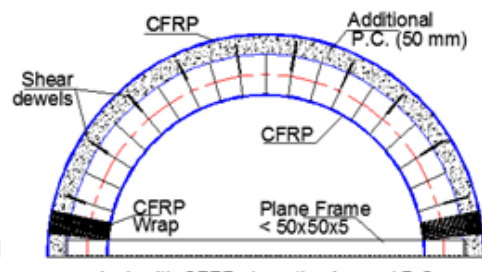

Arch with CFRP strengthening and P.C. (S-Arch-CFRP-Conc)

Fig. 5. Typical Strengthening Configurations for (S-Arch)

Table 3.

Description of Strengthening Configuration for Investigated Arches

\begin{tabular}{|c|l|}
\hline Specimen & \multicolumn{1}{c|}{ Strengthening Configuration } \\
\hline S-Arch & Semi-circle Arch with no strengthening \\
\hline S-Arch-CFRP & Semi-circle Arch with CFRP sheets at both the extrados and intrados surfaces \\
\hline S-Arch-CFRP-Conc & $\begin{array}{l}\text { Semi-circle Arch with 50 mm concrete at the intrados followed by CFRP } \\
\text { sheets at both the extrados and intrados surfaces }\end{array}$ \\
\hline Q-Arch & Quarter-circle Arch with no strengthening \\
\hline Q-Arch-CFRP & Quarter-circle Arch with CFRP sheets at both the extrados and intrados surfaces \\
\hline Q-Arch-CFRP-Conc & $\begin{array}{l}\text { Quarter-circle Arch with 50 mm concrete at the intrados followed by CFRP } \\
\text { sheets at both the extrados and intrados surfaces }\end{array}$ \\
\hline
\end{tabular}

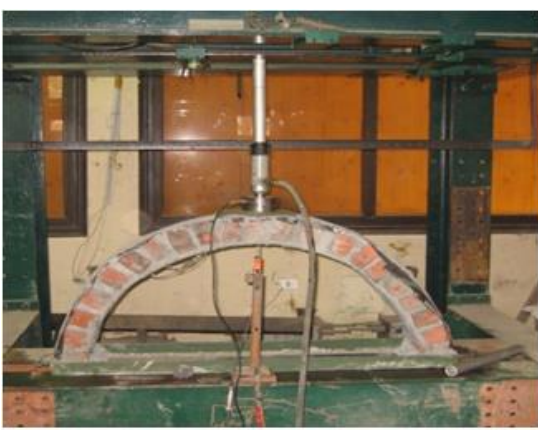

(a)

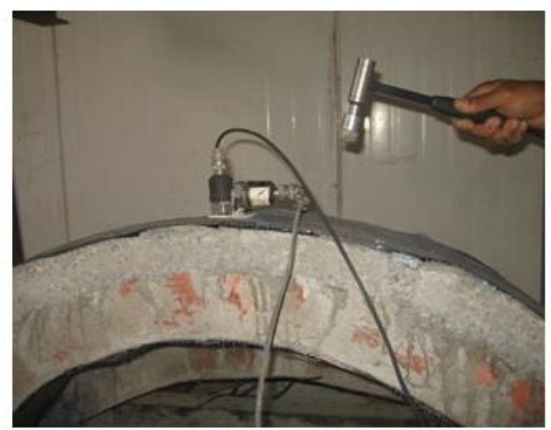

(b)

Fig. 6. a) Static Loading Test Setup, and b) Dynamic Testing of Masonry Arches 


\section{Results and discussions}

\subsection{Static test results}

\subsubsection{Masonry beams}

For all masonry beams, the load, strain and deflection at the mid-span of all beams were monitored and compared. Figures $7 \mathrm{a}$, and $\mathrm{b}$ show the load-deflection, and load-strain curves for all tested beams, respectively. It was noted that the load carrying capacity of the beam strengthened with CFRP only (MAS_CFRP), and with both CFRP and concrete together (MAS_CFRP_CONC), were 3.41 and 10.9 times that of the control specimen (MAS). The slope of the load- deflection curves showed the high stiffness of (MAS_CFRP_CONC) over (MAS_CFRP). Moreover, the much higher strain obtained in (MAS_CFRP_CONC) indicated the enhancement of ductility of the specimen over the rest of the examined beams. It was also clear that the failure mode of (MAS) was pure flexure occurred in the middle third of the beam at the interface joint between mortar and bricks. Actually, the current strengthening techniques overcame the unfavorable flexure failure due to the weakness of the mortar-masonry interface in transmitting the tensile forces. The use of sandwich like CFRP strengthening played an important role in preserving the integrity of the masonry beams; the fibers along the tensile soffit retarded the generation of cracks till certain strain after which the CFRP bears all the tensile stress till failure occurred. Whereas, the fibers along the compression surface slightly enhance the ductility of the beam. It was noticed that the conventional flexure failure was prevented. Shear failure between mortar and bricks occurred instead. Thus, the sandwich like CFRP strengthening worked as a wrap to the joined blocks of bricks and optimize the group action of bricks till failure occurred. In order to overcome both flexure and/or interfacial shear failure at the brick-mortar interface; a thin layer of plain concrete was added prior to application of CFRP at the compression side. It was also shown that adding plain concrete layer played an important role in improving the shear resistance, redistributing the load among all the bricks, and enhancing the overall stiffness of the masonry beams, i.e. it gave the sandwich a sort of rigidity. The failure of specimen (MAS_CFRP_CONC) showed that the failures occurred previously has been replaced by a pure shear failure in the brick unit itself followed by interfacial debonding of plain concrete over the cracked portion of bricks. Figure 8, shows the mode of failure occurred for masonry beams.

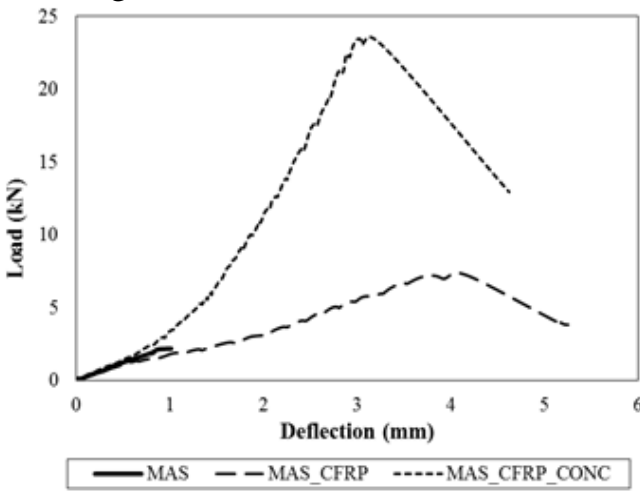

(a)

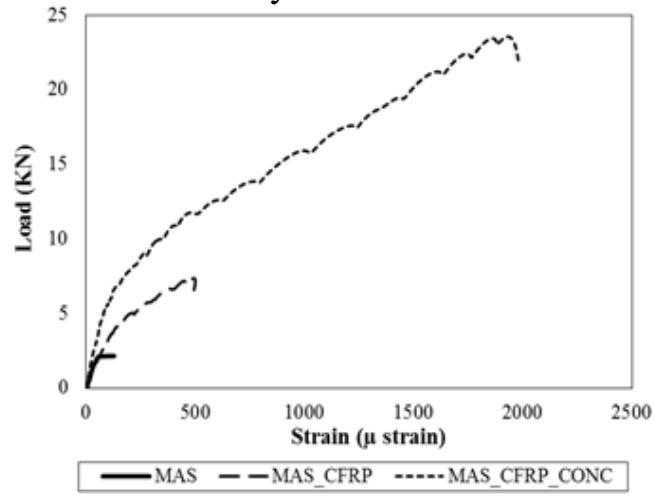

(b)

Fig. 7. (a) Load-Deflection and (b) Load-Strain Curves for Masonry Beams 


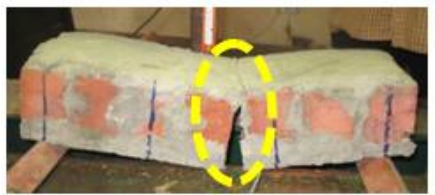

(a)

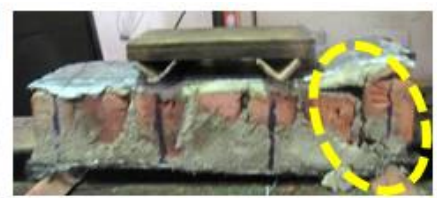

(b)

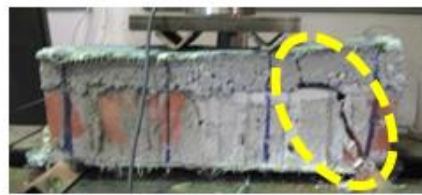

(c)

Fig. 8. Failure Modes for Masonry Beams with (a) no Strengthening, (b) CFRP Sandwich Strengthening, and (c) Concrete and CFRP Sandwich Strengthening

\subsubsection{Masonry arches}

Generally, it has been reported by many researchers $[1,2]$ that the typical failure mode of masonry arches is associated with the formation of number of hinges failure mechanism. The hinges, which behave like pins, turn the structure into a weak mechanism where the arch can be divided into block segments that can rotate one with respect to the other and consequently collapsing the whole arch. In the current research, both (S-Arch) and (Q-Arch) have been collapsed with almost the same behavior. Figure 9, shows the failure of non-strengthened arches. It is however, noted that the semi-circle arch collapsed suddenly and totally after creating the hinges and reached its maximum loading capacity. Whereas, the quarter circle arch developed further little strains more after developing the hinges prior to failure. It has also been reported [2] that the slippage between the mortar and bricks is also a possible mode of failure that can be reached before failure of the brick elements themselves. Thus, the current work addresses new techniques to activate the group action of masonry arches and help in preventing and/or minimizing the mortar-brick interface failure.
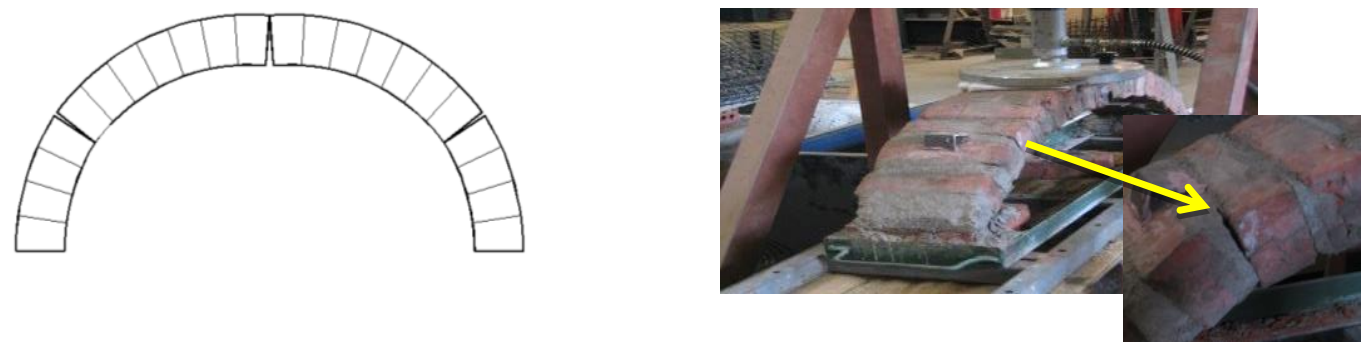

Fig. 9. Typical Hinged Failure Mechanism for S-Arch and Q-Arch Followed by Sudden Collapse of Arch

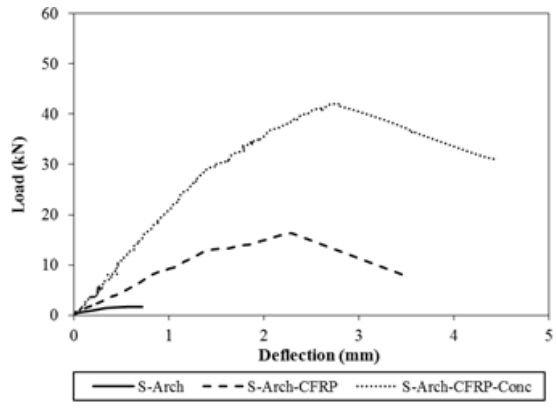

(a)

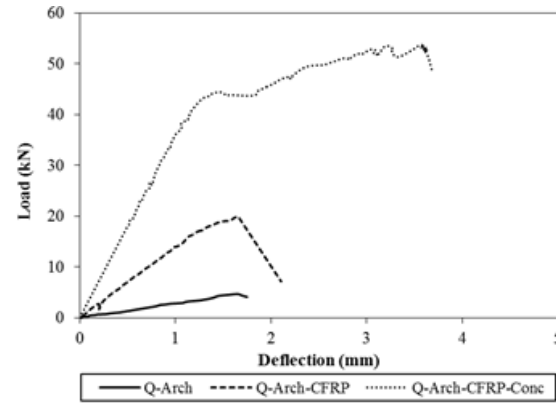

(b)

Fig. 10. Load deflection curves for: (a) Semi-circle Arches, and (b) Quarter circle Arches

The Load-Deflection curves were plotted for the two sets of semi-circle and quarter circle arches and they are shown in Figures 10a, and b, respectively. In general, the quarter circle arch exhibited higher stiffness than semi-circle arch with the same opening width. The quarter circle arch exhibited 2.78 times more loading capacity than the semi-circle arch without any strengthening. This could be attributed to the nature of straining actions and flow of loads mechanism in both arches. The (Q-Arch) resisted the external vertical 
applied force by internal axial compression force that transmits the loads to the support causing big horizontal reactions. Whereas, the (S-Arch) the external load forced the arch to deform laterally and consequently accelerated the formation of hinges.

In general, the load carrying capacity of all examined arches achieved much higher values than their control specimens. For Semi-circle arches, it was noted that the load carrying capacity for (S-Arch-CFRP) and (S-Arch-CFRP-Conc) exerted 9.72, and 24.96 times more than the original arch with no strengthening (S-Arch). Whereas, the quarter circle arches (QArch-CFRP) and (Q-Arch-CFRP-Conc) reached 4.25, and 11.39 times the load carrying that of the control (Q-Arch). It was also clear that the efficiency of strengthening of semi-circle arches was almost more than twice those of the quarter circle arches.

The modes of failure of the strengthened arches are shown in Figure 11. It was clear that the formation of multi-hinges mechanism was avoided and a better arch performance was achieved. For (S-Arch-CFRP), the crack started in the vicinity of the load at the mortar-brick interface causing concentration of stresses in the CFRP sheet at the intrados surface followed by interfacial debonding and this matched with previously reported [16]. Successively, slippage between mortar-brick interface at the left base of the arch due to horizontal force was captured. For (QArch-CFRP), no horizontal slippage was monitored; however, interfacial shear failure at mortarbrick interface occurred at vicinity of the load till the intrados surface leading to interfacial debonding of CFRP sheet. For (S-Arch-CFRP-Conc), the crack started from the load application point and thoroughly cut the brick unit itself in shear mode till reaching the intrados surface where debonding of CFRP sheet occurred. The performance of (Q-Arch-CFRP-Conc) exhibited the best performance among all strengthening conditions. Occurrence of interfacial debonding has no longer being existed, group of flexure-shear cracks starting from load application point through the plain concrete, crossing bricks and mortar till the right support. The shear failure in bricks revealed that the failure started after reaching the maximum capacity of the constitutional materials. This indicated that this strengthening mechanism worked in increasing the efficiency of the strengthened masonry arch. It was also shown that no signs of slippage were noticed. The thin layer of plain concrete works in redistribution of the applied load along the extrados surface and prevented any concentrations in the stresses. Moreover, it increased the overall stiffness of the arch and confined the arch causing enhancement of the group action of the bricks.

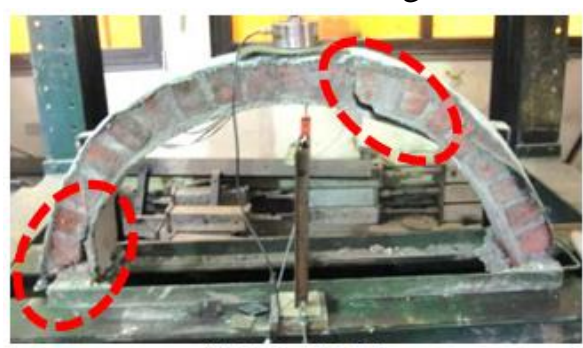

(S-Arch-CFRP)

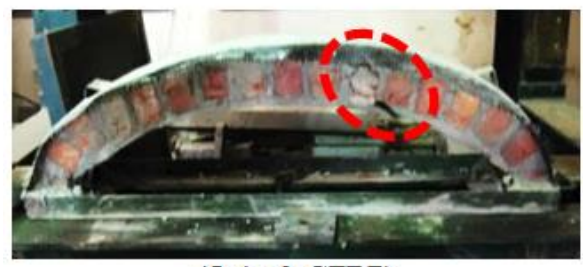

(Q-Arch-CFRP)

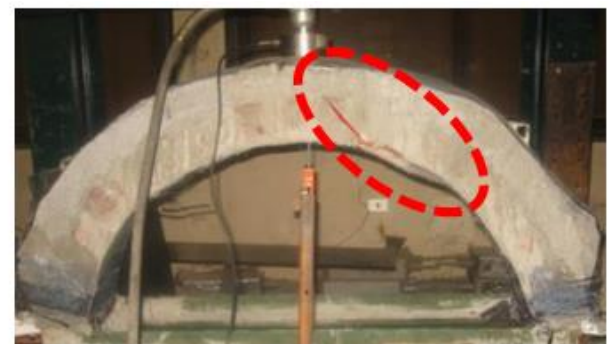

(S-Arch-CFRP-Conc)

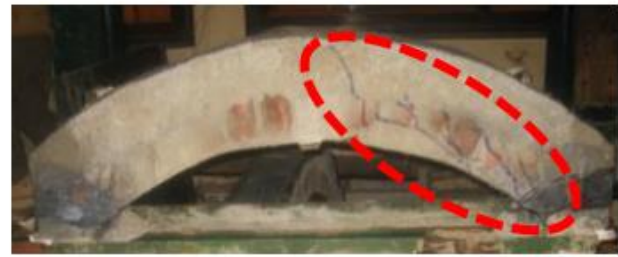

(Q-Arch-CFRP-Conc)

Fig. 11. Modes of Failure for Strengthened Arches 


\subsection{Dynamic test results}

The dynamic evaluation of masonry arches is not of less importance than that of the static. Practical wise, arches might be subjected to cycles of continuous vertical loads such as traffic with their dynamic effect. In addition seismic forces with vertical and horizontal components can also affect their efficiency. Therefore, it was of great importance to study the effect of strengthening on the dynamic performance of masonry arches. In the current research, acceleration time histories, in vertical direction, were collected at the crest of arches due to impact by a light mass hummer. Figures $12 \mathrm{a}$, and b show a sample of records measured for (S-Arch) and (Q-Arch), respectively. It can be easily noticed that the damping ratio for (Q-Arch) was much higher than (S-Arch). Particularly, the high rigidity of the arch with less curvature (Q-Arch) played an important role in restoring the arch to its original position in shorter time. Modal analysis, using Fast Fourier Transformation FFT, was conducted. The Fourier spectrum for all specimens before and after strengthening were plotted together to facilitate the comparison. Figures 13a, and b, show the FFT plot for the examined specimens for (S-Arch) and (Q-Arch), respectively. The first two modes of all specimens were captured experimentally and reported in Table 4.

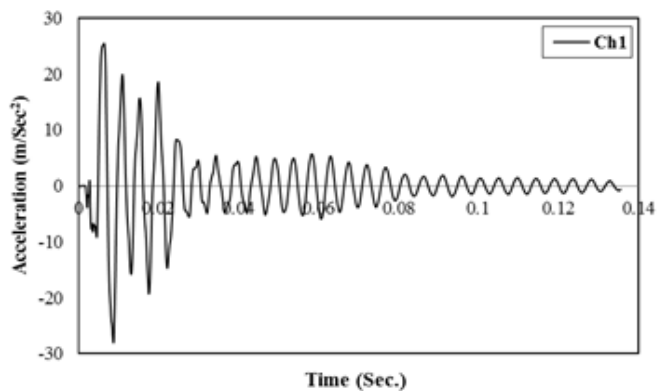

(a)

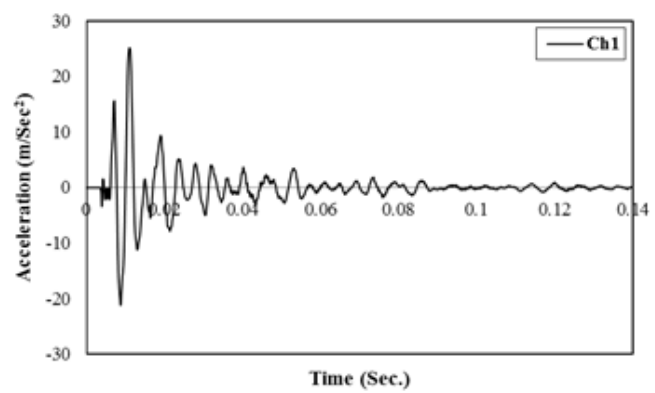

(b)

Fig. 12. Acceleration-Time History for: a) (S-Arch), and b) (Q-Arch)

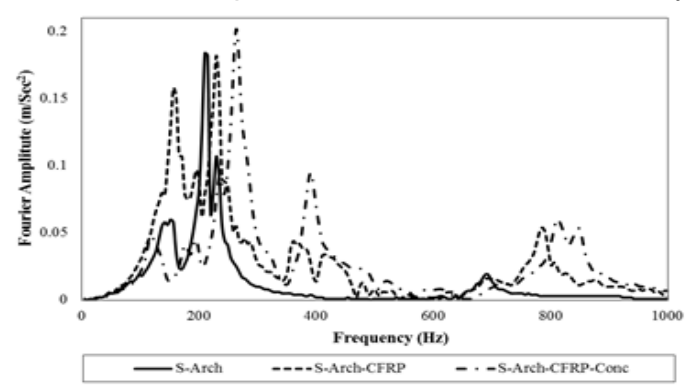

(a)

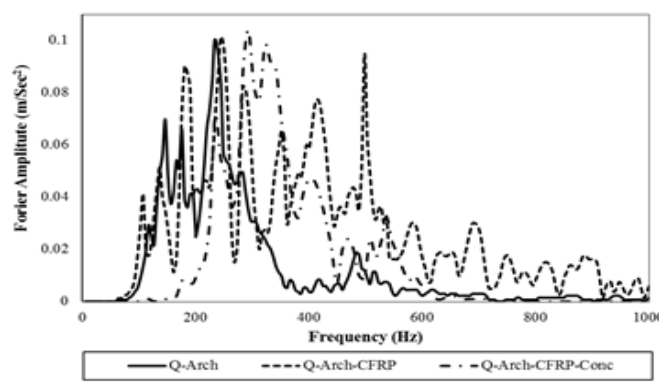

(b)

Fig. 13. Fourier Spectrum for (S-Arch) and (Q-Arch)

For better understanding the dynamic behavior of the arches, further numerical analysis by means of the Finite Element Analysis software, SAP2000 [17], was also conducted. Frame elements were used to model the arches. Each arch was discretized into reasonable number of frame elements. The values of the physical properties obtained experimentally were used in the simulation. The boundary conditions were set as hinged supports. Formal modal analysis for arches without any strengthening was simulated. The Finite element analysis was used just as an indicator and guidance for the values and shapes for the first two modes. In fact, the first mode was obtained showing an in-plane sway, whereas, the second mode was 
Ahmed M. Anwar, performance of masonry arches strengthened with CFRP sandwich

of pure bending behavior. The numerical work has proved good coincidence with the experimental frequencies. Table 5, shows the frequencies obtained numerically.

Table 4.

Fundamental Natural Frequencies for all Arches

\begin{tabular}{|c|c|c|c|c|c|c|}
\hline \multirow[t]{2}{*}{ Specimen } & \multicolumn{3}{|c|}{$\begin{array}{c}\text { First Mode } \\
\text { Frequency }(\mathrm{Hz})\end{array}$} & \multicolumn{3}{|c|}{$\begin{array}{l}\text { Second Mode } \\
\text { Frequency }(\mathrm{Hz})\end{array}$} \\
\hline & Before & After & Difference $(\%)$ & Before & After & Difference (\%) \\
\hline S-Arch & \multirow{3}{*}{209.961} & -- & -- & \multirow{3}{*}{371.094} & -- & -- \\
\hline S-Arch-CFRP & & 229.492 & 9.3 & & 380.859 & 2.6 \\
\hline $\begin{array}{l}\text { S-Arch-CFRP- } \\
\text { Conc }\end{array}$ & & 263.672 & 25.6 & & 390.625 & 5.3 \\
\hline Q-Arch & \multirow{3}{*}{234.375} & -- & -- & \multirow{3}{*}{478.516} & -- & -- \\
\hline Q-Arch-CFRP & & 244.14 & 4.2 & & 498.047 & 4.1 \\
\hline $\begin{array}{l}\text { Q-Arch- } \\
\text { CFRP-Conc }\end{array}$ & & 292.969 & 25.0 & & 537.109 & 12.2 \\
\hline
\end{tabular}

Table 5.

Fundamental Natural Frequencies for S-Arch and Q-Arch obtained numerically

\begin{tabular}{|c|c|c|}
\hline \multirow{2}{*}{ Specimen } & \multicolumn{2}{|c|}{ Frequencies of Fundemental Modes Obtained Numerically (Hz) } \\
\cline { 2 - 3 } & $1^{\text {st }}$ Mode & \\
\hline & & \\
\hline S-Arch & & \\
\hline Q-Arch & 206.133 & 403.205 \\
\hline
\end{tabular}

By comparing the natural frequencies obtained experimentally for (S-Arch) and (QArch) without strengthening, one can obtain that the (Q-Arch) was much stiffer, in elastic stage, by a ratio of $11.6 \%$, and $28.9 \%$ for the first two modes, respectively. Table 4 showed also that the enhancement in the dynamic properties in the vertical direction due to CFRP sandwich strengthening only was not significant. This could be attributed to the very small thickness of CFRP sheets with small flexural rigidity which might not significantly influenced the section overall rigidity in elastic stage. On the other hand, noticeable enhancement in arches strengthened with a layer of concrete along with CFRP sandwich, especially at the first mode. This could be attributed to the effect of increasing the arch stiffness due to the increase of concrete thickness overlaying the arches.

\section{Conclusions}

The current research suggested utilization of CFRP sheets for strengthening of masonry arched structures in sandwich form. CFRP alone or together with plain concrete layer was used for strengthening purpose. Static and dynamic evaluations were conducted. The current research shows that the effectiveness of strengthening of semi-circle arch was found, in general, much better than that of quarter circle arch for the same strengthening configuration. The following are among the main findings of the research: 
1- The quarter circle arch exhibited higher load carrying capacity than semi-circle arch by $178 \%$ for the same opening span and without strengthening.

2- Sandwich strengthening with CFRP sheets only enhanced the global group action of bricks leading to better arch performance. The strengthened arches achieved 9.72 and 4.25 times the load carrying capacity over their controls for both (S-Arch) and (Q-Arch), respectively.

3- Adding thin layer of plain concrete prior to CFRP application at the extrados surface played an important role in distributing of load and prevented stress concentration among the strengthened arches. The strengthened arches achieved 24.96 and 11.39 times the load carrying capacity over their controls for both (S-Arch) and (Q-Arch), respectively.

4- For all strengthened arches, no sudden collapse was achieved just after reaching the maximum load. The formation of hinges mechanism at failure was prevented. This shows the enhancement in the ductility of the strengthened arches in releasing the gained energy during loading.

5- The dynamic test showed that the enhancement in the natural frequency of arches strengthened with CFRP alone was not as much as the case where a layer of plain concrete was added to the sandwich strengthening.

6- The numerical model results proved good coincidence with the physical model and were of a good guidance in determining the arches natural frequencies.

\section{REFERENCES}

[1] Ilaria Cancelliere, Maura Imbimbo, Elio Sacco, "Experimental tests and numerical modelling of reinforced masonry arches”, Engineering Structures, Vol. 32, 2010, pp. 776 - 792.

[2] Y. Tao, T.J. Strarford, J.F. Chen, "Behaviour of masonry arch bridge repaired using fibrereinforced polymer composities", Engineering Structures, Vol. 33, 2011, pp. 1594 - 1606.

[3] Ismet Calik, Alemdar Bayraktar, Temel Turker, Halil Karadeniz, "Structural dynamic identification of a damaged and restored masonry vault using Ambient Vibratons", Measurments, Vol. 55, 2014, pp. $462-472$.

[4] Foraboschi P. Strengthening of masonry arches with fiber-reinforced polymer strips. J Compos Construct, Vol. 8(3), 2004, pp. 191-202.

[5] Juntao Kang, Xuefeng Wang, Jian Yang, Yingang Du, "Strengthening double curved arch bridges by using extrados section augmentation method", Construction and Building Materials, Vol. 41, 2013, pp. $165-174$.

[6] Laura Anania, Antonio Badala, Giusppe D' Agata, "The post strengthening of the masonary vaults by the $\Omega$-Wrap technique based on the use of C-FRP", Construction and Building Materials, Vol. 47, 2013, pp. 1053 - 1068.

[7] Angelo D'Ambrisi, Luciano Feo, Francesco Focacci, "Masonry arches strengthened with composite unbonded tendons", Composite Structures, Vol. 98, 2013, pp. 323 - 329.

[8] Francesca Giulia Carozzi, Gabriele Milani, Carlo Poggi, "Mechanical properties and numerical modeling of Fabric Reinforced Cementitious Matrix (FRCM) systems for strengthening of masonry structures", Composite structures, Vol. 107, 2014, pp. $711-725$.

[9] L. Garmendia, J.T. San-Jose, D. Garcia, P. Larrinaga, "Rehabilitation of masonry arches with compatible advanced composite material", Construction and Building Materials, Vol. 25, 2011, pp. $4374-4385$.

[10] Claudio Maruccio, Ismael Basilio, Daniel V. Oliveira, Paulo B. Lourenco, Giorgio Monti, "Numerical modelling and parametric analysis of bond strength of masonry members retrofitted with FRP”, Construction and Building Materials, Vol. 73, 2014, pp. 713 - 727. 
[11] Nino Spinella, Piero Colajanni, Antonino Recupero, "Experimental in situ behaviour of unreinforced masonry elements retrofitted by pre-tensioned stainless steel ribbons", Construction and Building Materials, Vol. 73, 2014, pp. 740 - 753.

[12] Antonio Borri, Giulio Castori, Marco corradi, "Intrados strengthening of brick masonry arches with composite materials", Composites: Part B, Vol. 42, 2011, pp. 1164 - 1172.

[13] Alemdar Bayraktar, Temel Turker, Ahmet Can Altunisik, "Experimental frequencies and damping ratios for historical masonry arch bridges", Construction and Buildings Materials, Vol. 75, 2015, pp. $234-241$.

[14] Ferit Cakir, Habib Uysal, "Experimental modal analysis of brick masonry arches strengthened prepreg composities", Journal of Cultural Heritage, Vol. 16, Issue 3, 2015, pp. 284-292.

[15] Wei Xie, Meirong Jiang, Hailong Chen, Jiannan Zhou, Ying Xu, Peng Wang, Hualin Fan, Fengnian Jin, "Experimental behaviors of CFRP cloth strengthened buried arch structure subjected to subsurface localized explosion", Composite structures, Vol. 116, 2014, pp. $562-570$.

[16] Maalej M. and Leong K.S., "Effect of Beam Size and FRP Thickness on Interfacial Shear Stress Concentration and Failure Mode of FRP-Strengthened Beams", Composites Science and Technology, 65, 2005, pp. 1148-1158.

[17] SAP2000, User manual, Ver. 14.2.2, Computers and Structures, Inc., 2010. 


\section{أداء القباب المبنية من الطوب الطيني بعد تقويتها باستخلام ساندويتش من بوليمارات الفيبر الكربوني}

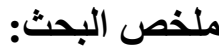

يمثل اختيار المواد المناسبة لتدعيم ورفع كفاءة المنشآت القبابية المبنية من وحدات الطوب الطيني أهمية

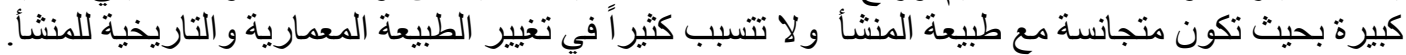

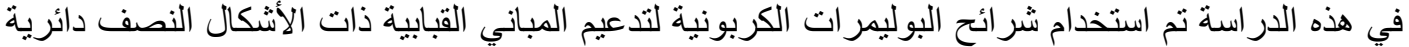

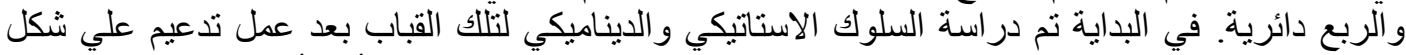

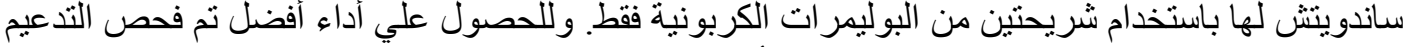

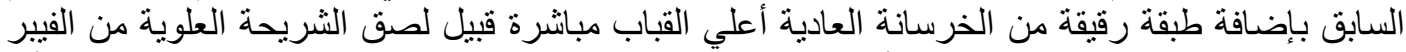

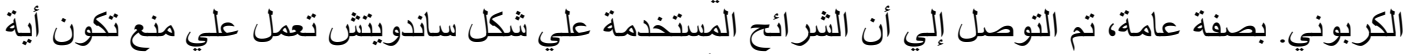

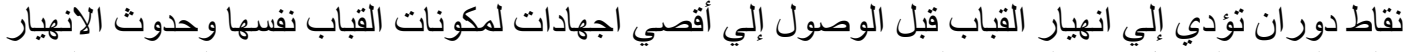

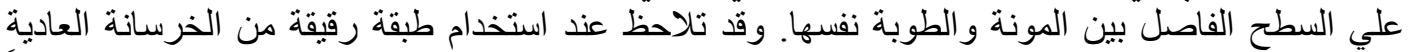

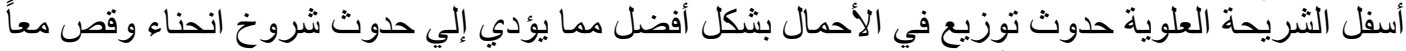

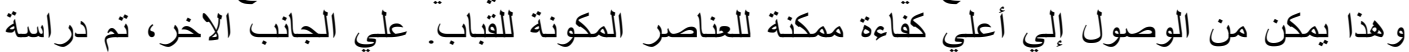

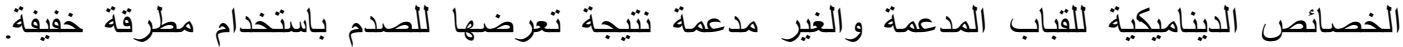

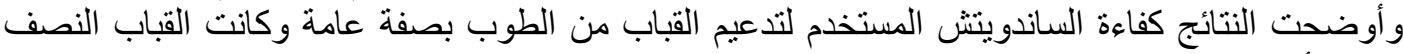
دائرية أعلي استجابة للتدعيم من القباب الربع دائرية لنفس نو عية التدعيم. لتبن التبن 